\title{
Justification of the Model of Innovative Development of the Enterprise
}

\author{
Olga Gonchar \\ Professor of the Department of \\ Economics of Enterprise and \\ Entrepreneurshipdept \\ Khmelnytsky, Ukraine \\ o.i.gonchar@i.ua \\ http://orcid.org/0000-0003-3917-7586
}

\author{
Alla Cherep \\ Dean of the Faculty of Economics \\ Zaporizhzhia National University \\ Zaporizhzhia, Ukraine \\ cherep.av.znu@gmail.com \\ http://orcid.org/0000-0001-5253-7481
}

\author{
Alexander Cherep \\ Professor of Marketing and Personnel \\ Management \\ Zaporizhzhia National University \\ Zaporizhzhia, Ukraine \\ cherep2508@gmail.com \\ http://orcid.org/0000-0002-3098-0105
}

\begin{abstract}
It is established that in developing the models of innovation activity (IA) it is expedient to develop the economic mechanism (EM) as an instrument of further innovation development, which will allow the company to achieve its objectives. It is defined that in the process of analysis in determining the parameters of the model of innovation activity it is advisable to find out the advantages and disadvantages of all criteria of the model, which fully correspond to the established parameters. They allow to characterize the aspects of the company, identified by each component of the model and timely eliminate defects before the building of the mechanism of innovation activity of industrial enterprises (MIAIE). The relations between the criteria of the components of the model and their indicators are determined by taking into account the available information on financial and economic activity, the innovative development of the main areas of activity, the identified threats and risks, the isolated parameters and regularities during the choosing the components and criteria of the model. The MIAIE based on the selected components, criteria and indicators, has been developed by establishing the conformity of the selected components to the developed model parameters and taking into account the achieved value of the economic-informational, innovative-social, organizational-ecological components on the calculated indicators, and also on the basis of the achieved effects from the IA.
\end{abstract}

Keywords- Parameters of innovation model, criteria, components, economic mechanism, factors, interaction, effect, development

\section{INTRODUCTION}

Innovation activity today is a major factor in improving the functioning of not only industry, sector, but also of the economic activity of the country as a whole. The deterioration of financial activity of enterprises, the need of decision of existing problems of business entities form the need for the development of innovation activities, which will improve the organization's image, strengthen competitive positions [1]. Improvement of innovation activity affects the organization of the production process, the technological level, the activity of the marketing department [2]. In this case, the construction of the model of IA influences the efficiency of activities, allows to explore the features of the operation of the enterprise, to determine the list of threats, to assess the achieved level of innovation development. Today, existing models are not adapted to the conditions of operation of enterprises and their implementation is not always possible. The development of EM in the construction of an IA model for mechanical engineering enterprises is a topical issue, since it will contribute to achieving the desired effect from the introduction of such a model $[3,4,5]$.

\section{StATEMENT OF THE PROBLEM}

In our opinion, the existing models are not adapted to the conditions of operation of the machine-building enterprises and therefore their use is not always possible, they do not also take into account the use of EM. Therefore, despite numerous studies on the process of modeling innovation development, the issue of developing and using an IA model based on the use of EM is still undecided, about the model taking into account the sphere of activity, directions of innovation development, the peculiarities of the enterprises of the mechanical engineering industry in the Zaporizhzhia region, the factors influencing the IA $[6,7,8]$.

The purpose of the article is to specify the parameters and clarify the elements of building a model of innovative development of the enterprise.

\section{RESULTS}

Uncertainty and riskiness are important features of enterprise innovation processes in today's operating environment. During the innovation activity of the enterprise at all stages: development, implementation and application of innovations, there is a high probability of an unfavorable situation or deviation of the real result from the plan. This can lead to unplanned costs, losses arising from the investment of the enterprise in the production of new goods or services, the change of technologies, in the development of new technology, in the investment of funds in the development of managerial innovations that will not have the desired effect. This is what creates innovative risks $[10,11]$.

The objective function of innovation risk management consists in the development and implementation of management decisions aimed at identifying, identifying and preventing and effectively solving the risk situations arising in the process of innovation. Namely: restoration of the initial state of the innovation process and tendencies of its positive development in the external environment at the lowest possible costs and losses.

The success of innovation risk management, both within a single innovation project and as a whole, is influenced by several interdependent factors, including: risk management organization; level of development of 
tools, methods and availability of funds for risk management; quality of implementation of risk management measures.

The high level of risk in innovation is due to the fact that innovative solutions, on the one hand, involve significant financing and, on the other, not all innovations implemented bring the expected economic result to the enterprise.

Risk in innovation should be understood as the threat of the enterprise losing part of its resources, lack of income or additional costs resulting from the implementation of economic and financial activities that use new technologies, involves the release of new goods, services, the use of new ways of their implementation, etc.

In order to effectively manage innovation risk, it is necessary to have a strategic plan in place for sound and consistent actions that would determine the specificization of activities and what methods and measures should be applied.

Innovation risk management should be understood as a set of practical actions that are grounded on the principles, methods and tools of management decision-making, taking into account the defined performance criteria, and which reduce the uncertainty of innovation performance and increase its efficiency.

The main task of managing innovative risks is to minimize the additional costs and losses associated with emerging discrepancies. For different types of innovation, the risk management process should include the following steps:

- identification of possible innovation risks, their identification and classification,

- determining the likelihood of each such risk,

- risk analysis and assessment,

- risk assessment,

- developing risk mitigation measures and ways to respond to identified and assessed risks,

- monitoring the implementation of decisions or projects,

- implementation of tactical decisions on risk management.

The identification of innovation risks is to understand what events may have a negative impact on the activity, ie to identify potential sources of innovation risk. The list of such negative events should be comprehensive.

In determining the parameters of the model of innovation, it is advisable to find out the advantages and disadvantages of the selected criteria of the model, which involves undertaking an analysis of the enterprise according to the criteria and based on the results of the analysis of the definition of a list of criteria that fully correspond to the parameters of the model and allow to characterize those aspects of the enterprise defined by each component of the model [9].
Carrying out such analysis allows to identify the main shortcomings during the choosing criteria and timely eliminate them before building the MIAIE).

At the next stage, the relationships between the criteria of the components of the model and their indicators are determined by taking into account the available information on financial and economic activity, the innovative development of the main areas of activity, the identified threats and risks, the isolated parameters and regularities when choosing the components and criteria of the model. In this case, the functional relationships between the criteria of the components of the MIAIE will look like formula (1-3):

$$
E I C=\frac{F C+E C}{n_{i}}
$$

where: EIC - the economic and informational component of the model; $F C$ - financial criterion; $E C$ economic criterion; $n_{i}$ - total number of criteria.

Simultaneously:

$$
I S C=T C+\frac{\operatorname{InInvC}}{n_{i}}
$$

where: $I S C$ - is an innovative social component;

$T C$ - technological criterion;

$I_{n} I_{n v} C$ - innovation-investment criteria.

Organizational-ecological component (OEC) is based on the study of production (PC) and marketing criteria (MC) by calculating indicators according to these criteria.

The study of this group of criteria is due to the need to determine the conditions necessary for the improvement of innovation development, that is, the establishment of the level of equipping the production process with modern equipment, technology, efficiency of the process of promotion of new products to the markets, [7] the effectiveness of advertising measures, compliance with the norms of product quality, norms of emissions of pollutants, find out the possibilities for expanding the range of products and the rationality of the organization of production activities.

$$
O E C=\frac{P C-M C}{n_{i}}
$$

where: $O E C$ - is an organizational and ecological component; $P C$ - production criteria; $M C$ - marketing criteria.

To calculate each selected criterion of the model, the arithmetic mean of the corresponding indicators was determined (formulas 4-6), where $n_{i}$ is the total number of indicators of the required criterion;

$$
\begin{aligned}
& E C=(\text { NSIInna }+ \text { WCIa }+ \text { VIP }+ \text { GLP }+P A+P I P) / n_{i}+ \\
& +(L A P+\text { SPIA }+ \text { PRF }+ \text { RIInn }+ \text { SiR }) / n_{i}
\end{aligned}
$$




$$
\begin{aligned}
& E C=\frac{C S I M T+C P T+R C T I A+U T I+I O E I T+I E A+I r P P}{n_{i}} \\
& \operatorname{InInvC}=(E U L R+L P+E E n I I n A+R \operatorname{Rinl}+P I P+P I A) / n_{i}+ \\
& +(E K К \kappa Д \Phi+R H S S W i n S W+V I P+R I E+C o l) / n_{i}
\end{aligned}
$$

The establishment of functional relationships among the criteria of the components of the MIAIE is carried out in order to determine the level of interaction between the indicators of each criterion, the feasibility of their choice, the level of their influence on the desired size of the corresponding criterion of the model, which will ultimately contribute to determining the overall value of the formed components.

Determining the relationship among the indicators of selected criteria allows to determine the correctness of each indicator, the extent of each impact on the value of the criterion. In the absence of interaction among the indicators of each criterion, that is their influence is uncertain - there is a return to the previous stages for the choice of indicators that allow to calculate the desired criterion model.

At the next stage, the development of the MIAIE is carried out on selected components, criteria and indicators, by comparing them, establishing the conformity of selected components to the formed parameters of the model and taking into account the achieved value of the economic-informational, innovativesocial, organizational-ecological components on the calculated indicators, and also on the basis of comparison the achieved effects from the IA (fig. 1).

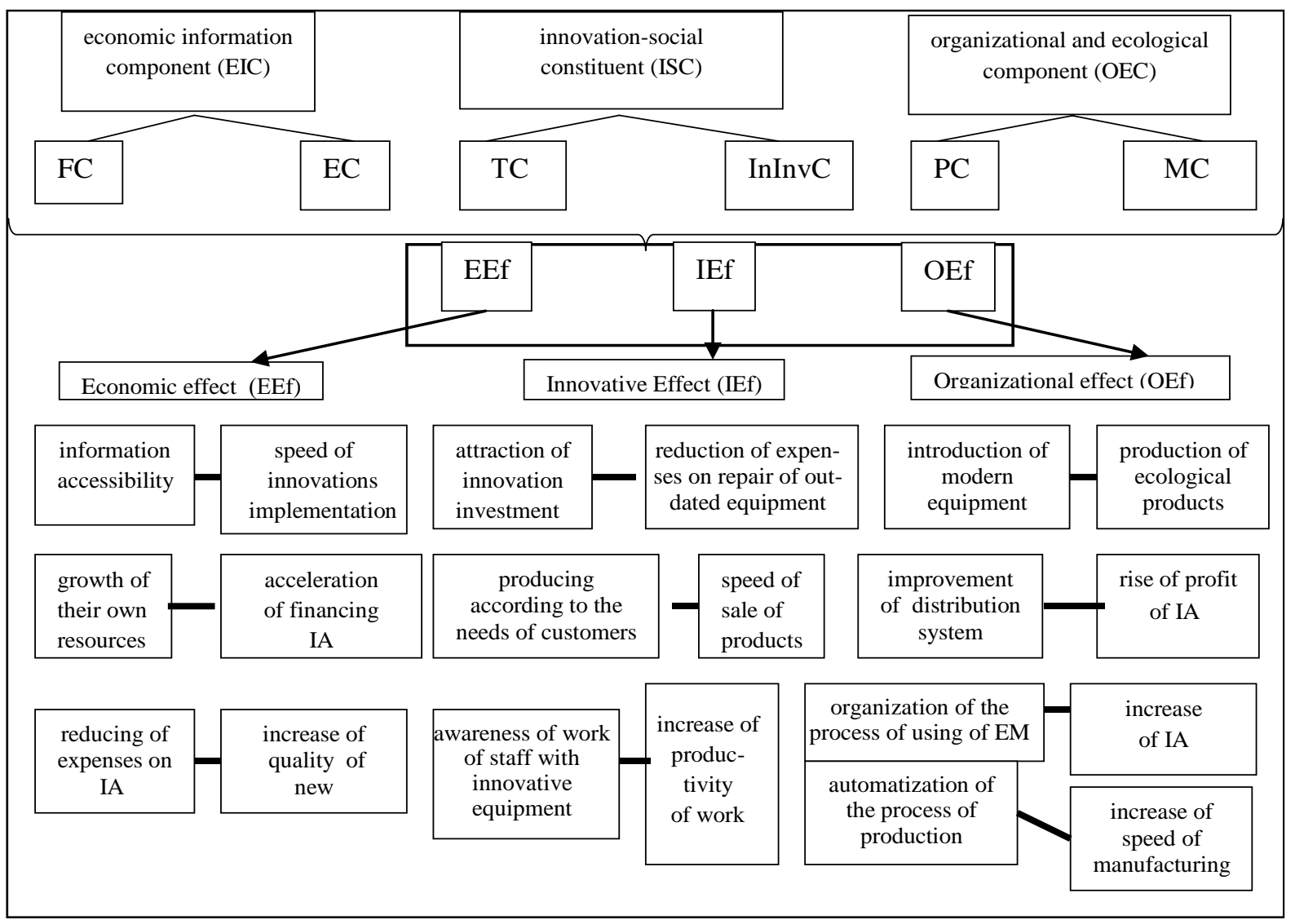

Fig. 1. Model of innovative activity of industrial enterprises through the use of an economic mechanism

The introduction of the MIAIE through the use of an economic mechanism at the machine-building enterprises is expedient, since the process of designing of several models objectively takes into account the peculiarities of the activity of the selected group of companies, permits to conduct the reliable analysis, allows to analyze and choose a more efficient model that will facilitate the restoration of the IA, the rational use of EM, achievement of economic, investment, organizational effects and identification of the main directions of the IA, subject to the study of the environmental factors. The provided MIAIE will help to asses the company's capabilities to use it, solve the main problems of the machine engineering business, to compare of models indices over several periods and compare them with similar models. The determination of the components, criteria and indicators when developing the MIAIE is carried out on the basis of a comprehensive analysis of the company's activity and the ranking of the results obtained for each model avoids errors in choosing the model to be implemented at the selected enterprise, ensuring the maximum growth of the expected effects. 
It Also, this model should consider the feasibility of using EM in improving the IA. If the the MIAIE is developed without determining the need for the use of $\mathrm{EM}$, then there is a transition to the stage of formation of the purpose of modeling in order to establish its role in innovative development [10].

The next stage is characterized by the introduction of the MIAIE in the practice of the enterprise and the management of the company decides on the question of how to implement the developed model, as well as the feasibility of its use in a given enterprise. Next, there is a transition to the stage of evaluation of the results of the MIAIE, i.e. the degree of achievement of the expected effects from the implementation of the IA, the use of EM, the comparison of several MIAIEs is being studied and a more efficient model that satisfy the needs of the machine-building enterprise is selected. In addition, a ranking of the results obtained for each model, that is, components, criteria, determine the level of efficiency of the model, more efficient model is implemented on the basis of comparison of analyzed models. If none of the models allows to achieve the desired results, their correction and search for ways to increase the efficiency of these models is carried out.

The introduction of the MIAIE through the use of an economic mechanism at the machine-building enterprises is expedient, since the process of designing of several models objectively takes into account the peculiarities of the activity of the selected group of companies, permits to conduct the reliable analysis, allows to analyze and choose a more efficient model that will facilitate the restoration of the IA, the rational use of EM, achievement of economic, investment, organizational effects and identification of the main directions of the IA, subject to the study of the environmental factors.

The provided MIAIE will help to asses the company's capabilities to use it, solve the main problems of the machine engineering business, to compare of models' indices over several periods and compare them with similar models. The determination of the components, criteria and indicators when developing the MIAIE is carried out on the basis of a comprehensive analysis of the company's activity and the ranking of the results obtained for each model avoids errors in choosing the model.

\section{CONCLUSION}

Implementation of the MIAIE through the use of an economic mechanism aims at improving the process of organizing production, setting the level of productivity, using innovative technologies, restoring the system of product sales, attracting investment capital, which will solve the main problems in the subject of the business, improve the quality of customer service. In addition, within the implementation of the model, the aspect of financial, innovation development of the enterprise, social orientation is taken into account, the achieved indicators of production and economic activity for a certain period are determined, the expected results from the IA [6].

In the course of the research, we developed the model of innovative activity of the mechanical engineering enterprises (the MIAIE) by using the economic mechanism, the model is an instrument of development of the IA of the investigated enterprise, is based on the calculation of financial, economic, technological, innovation-investment, production, marketing criteria, includes economic and informational, innovative-social, organizational-ecological component, allows to carry out a comprehensive assessment, to rank the obtained results by the degree of profitability and implement it by observing the algorithm of its implemented at the selected enterprise, ensuring the maximum growth of the expected effects.implementation, considering the factors of the environment, which enables to raise the level of competitiveness, organize and regulate the process of IA, achieve long-term goals of the activity, receive economic, investment, organizational effects due to the compliance with the main tools, principles, methods, use of functions of the economic mechanism.

\section{REFERENCES}

[1] V.V. Macedon, and D.S. Rubets, "Strategic Innovation Development: Theory and Methodology", Herald in of the National Technical University "KhPI". Series: Technical Progress and Production Efficiency, no. 45 (1018), pp. 75-86, 2013.

[2] L.I. Fedulova, Classification of innovative strategies, 2016. [Online]. Available: http://dspace.nuft.edu.ua/jspui/bitstream/ 123456789/10837/1/Classification of innovation.pdf. Accessed on: July 20, 2019.

[3] O.I. Khomenko, "Types of strategies and tools for forming a strategy for enterprise development". Development Management, vol. 3 (181), pp. 131-137, 2015 .

[4] H.Guo, Z.Su, and D. Ahlstrom, "Business model innovation: The effects of exploratory orientation, opportunity recognition, and entrepreneurial bricolage in an emerging economy", Asia Pa. J. Manag., 2016, [Online]. Available: https://doi.org/10.1007/ s10490-015-9428-x. Accessed on: July 19, 2019.

[5] A.J. Fusari, "A model of the innovation-adaptation mechanism driving economic dynamics: a micro representation", Evol Econ, 2005. [Online]. Available: https://doi.org/10.1007/s00191-0050246-z. July 20, 2019.

[6] A.V. Cherep, O. G.Cherep and, Y.O. Shvets, "Improvement of the scientific and methodological approaches for the development of economic mechanism of innovative activity of industrial enterprises in the conditions of market environment's", Financial and Credit Activity: Problems of Theory and Practice, vol. 4, no. 27, pp. 418-427, 2018.

[7] O.I. Gonchar, "Activation of business activity in the management of innovation and enterprise investment potential", Scientific bulletin of Polissia, vol. 4 (8), pp. 262-267, 2016.

[8] I.M. Chuchina, and S.M. Ivanova, "Formation of organizational and economic mechanism of innovation potential of the enterprise", Bulletin of the KPPO named after Mikhail Ostrogradsky, vol, 2 (55), no.1, pp. 117-120, 2009.

[9] L. Y. Basovskaiy, and Y. N. Basovskaya, Economic evaluation of the investment. Moscow^ INFRA-M, 2007.

[10] I. V. Demkin, "Management of innovation risk based on imitation modeling", Problems of risk analysis, vol. 2, no. 3, pp. 2-51, 2011.

[11] M.V. Gracheva, Risk Management in Innovation, Moscow: UNITI - DANA, 2010 